\title{
Mitral regurgitation in patients with aortic stenosis undergoing valve replacement
}

Philippe Unger, Chantal Dedobbeleer, Guy Van Camp, Danièle Plein, Bernard Cosyns and Patrizzio Lancellotti

Heart published online 24 Mar 2009;

doi:10.1136/hrt.2009.165548

Updated information and services can be found at:

http://heart.bmj.com/cgi/content/abstract/hrt.2009.165548v1

\section{These include:}

Rapid responses You can respond to this article at:

http://heart.bmj.com/cgi/eletter-submit/hrt.2009.165548v1

Email alerting Receive free email alerts when new articles cite this article - sign up in the box at the service top right corner of the article

Notes

Online First contains unedited articles in manuscript form that have been peer reviewed and accepted for publication but have not yet appeared in the paper journal (edited, typeset versions may be posted when available prior to final publication). Online First articles are citable and establish publication priority; they are indexed by PubMed from initial publication. Citations to Online First articles must include the digital object identifier (DOIs) and date of initial publication.

To order reprints of this article go to:

http://journals.bmj.com/cgi/reprintform

To subscribe to Heart go to:

http://journals.bmj.com/subscriptions/ 
Mitral regurgitation in patients with aortic stenosis undergoing valve replacement

Philippe Unger ${ }^{1}$, Chantal Dedobbeleer ${ }^{1}$, Guy Van Camp ${ }^{2}$, Danièle Plein ${ }^{3}$, Bernard Cosyns ${ }^{4}$, Patrizio Lancellotti ${ }^{5}$

${ }^{1}$ Department of Cardiology, ULB-Erasme Hospital, Brussels, ${ }^{2}$ Department of Cardiology, Universitair Ziekenhuis-UZ Brussel, Brussels, ${ }^{3}$ Department of Cardiology, Clinique SaintJean, Brussels, ${ }^{4}$ Department of Cardiology, CHIREC-Hôpital de Braine-l'Alleud,

${ }^{5}$ Department of Cardiology, Centre Hospitalier Universitaire Sart Tilman, Liège, Belgium

Key words: Aortic stenosis, mitral regurgitation, valvular surgery

Word count: 2932

Corresponding author:

Philippe Unger, MD

Cardiology Department, ULB-Erasme Hospital

808 route de Lennik, B-1070 Brussels, Belgium

Tel: +3225553907 , Fax: +3225554609

Email address: philippe.unger@erasme.ulb.ac.be 


\section{Summary:}

Mitral regurgitation is a frequent finding in patients with aortic stenosis scheduled for aortic valve replacement. Detection of mitral regurgitation in such patients has important implications, as it can independently affect functional status and prognosis. When mitral regurgitation is moderate-to-severe, a decision to operate on both valves should only be made following a careful clinical and echocardiographic assessment. Indeed, double-valve surgery increases peri- and post-operative risks, and mitral regurgitation may improve spontaneously after isolated aortic valve replacement. Better understanding of the determinants of these changes appears particularly crucial in the light of recent advances in percutaneous aortic valve replacement.

\section{Introduction}

At the time of aortic valve replacement (AVR), many patients with aortic stenosis (AS) exhibit varying degrees of mitral regurgitation (MR). The aetiology of the MR is often functional in nature, occurring in the absence of any significant intrinsic valvular lesion. Increased afterload, left ventricular (LV) remodelling, fluid overload and concomitant ischaemic heart dysfunction may account for the development of functional MR. When there is intrinsic mitral valve disease, this may result from calcification of the mitral leaflets or annulus, particularly in the elderly, but also from rheumatic involvement, or from myxomatous degeneration. MR associated with AS should not be overlooked, as it can worsen functional status and independently affect prognosis. Moreover, a surgeon's decision to operate on both valves should only be made after careful clinical and echocardiographic assessment, because double-valve surgery increases the perioperative risk, and MR can improve spontaneously after isolated AVR. Greater awareness of the determinants of these changes appears particularly crucial in the light of recent advances in percutaneous AVR. In this article, we review current knowledge on the pathophysiology, incidence, and prognostic value of MR in severe AS, as well as the natural history of MR after isolated AVR.

\section{Pathophysiology}

In patients with AS, the severity of MR increases over time in relation to the increase in transaortic pressure gradient.[1] When MR becomes moderate to severe, it may contribute to the development of heart failure symptoms. Severe AS may create or worsen MR through several mechanisms (Figure 1). First, it increases the LV to left atrial pressure gradient, and thereby increases the regurgitant volume for any given effective regurgitant orifice. Secondly, chronic pressure overload remodels the $\mathrm{LV}$, which in turn promotes mitral valve deformation. In addition, if severe, MR decreases forward stroke volume, thus reducing the aortic pressure gradient and making detection of AS more challenging ("low flow, low gradient" AS). Atrial fibrillation, which commonly complicates MR, may further reduce forward output and decrease the aortic pressure gradient. Finally, severe MR may impede the detection of subclinical myocardial dysfunction by preserving ejection phase indices of myocardial performance, such as left ventricular fractional shortening and ejection fraction.[2]

\section{Prevalence}

The cited prevalence of MR in patients undergoing AVR for AS varies among studies (Table 1).[3-10] These studies differ markedly 1) in their inclusion and exclusion criteria, some including patients with organic mitral valve disease [3-5,7] and others not; 2) in the method for MR assessment; and 3) in the threshold of MR severity used as an end-point (Table 1). Some degree of MR is found in as much as 61 to $90 \%$ of patients undergoing AVR for AS. 
More severe MR is far from exceptional. Ruel et al. reported that $\geq$ grade $2 / 4$ functional MR was found preoperatively in 13\% of 848 patients undergoing isolated AVR.[8] Barreiro et al. reported moderate MR in 17\% of 408 patients aged $\geq 70 \mathrm{y}$ undergoing isolated AVR.[7] In this population, MR was ischaemic or functional in $37 \%$, of myxomatous origin in $34 \%$, and associated with extensive valvular or subvalvular calcification in $29 \%$ of patients. Up to $74 \%$ of patients in a series by Waisbren et al. had moderate functional MR.[10]

\section{Prognostic value of MR in patients undergoing AVR}

The first report of simultaneous mitral and AVR was published by Cartwright and coworkers in 1963.[11] Severe organic MR leading to double-valve surgery is not infrequent, accounting for nearly $5 \%$ of all AVR.[12] Operative mortality for double-valve surgery is twice that of isolated AVR;[12-14] the sensitivity of the hypertrophied heart to ischaemia/reperfusion injury may contribute to this increased mortality. In the long-term, valve-related morbidity and mortality remain substantial.[14] Retrospective data reported by Gillinov et al. suggested that mitral valve repair during double-valve surgery might be beneficial compared to mitral replacement, with a long-term reduction in mortality (34\% versus $46 \%$ ), without increased peri-operative mortality.[15] Similarly, Talwar et al. reported that mitral valve repair with AVR provided significantly better event-free survival than double valve replacement.[16] When MR is less severe, and keeping in mind the good results of double valve surgery,[13] some groups have recommended an aggressive approach to operating on the mitral valve, supported by data showing that concomitant moderate to severe MR does not improve in half the patients, and that it even increases in a small subgroup of patients. $[4,6,17]$ Others support a more conservative approach, particularly in patients with functional MR, believing that repair or replacement is unnecessary unless patients clearly demonstrate severe MR.[3,17-20] The prognostic significance of "less than severe" MR in patients undergoing isolated AVR is debated. Caballero-Borrego et al. reported increased perioperative morbidity (infections, kidney failure, and low output) and mortality in patients with preoperative MR.[9] In contrast, several reports have documented minimal or no impact on early morbidity when there is no intervention on the mitral valve.[3,17-20] Moreover, in a rather limited population undergoing isolated AVR (58 patients with and 58 patients without grade 2-3+ preoperative MR), Absil et al. found no significant impact of MR on perioperative morbidity and mortality or on midterm survival (mean duration of follow-up 3.2 years).[20] Ruel et al. reported that patients with AS and $\geq$ grade $2+$ functional MR with left atrial diameter $>5 \mathrm{~cm}$, peak aortic gradient < $60 \mathrm{~mm} \mathrm{Hg}$ or atrial fibrillation, had a higher risk of mortality, congestive heart failure, or need for secondary mitral valve surgery after AVR.[8] In AS, it has been shown that the increase in severity of MR during exercise is associated with exercise-induced symptoms.[21] Whether such a dynamic increase, which is of prognostic importance in patients with functional MR,[22,23] may influence patient outcome in AS has never been examined. However, it should be emphasized that exercise testing is precluded in truly symptomatic patients with severe AS. In such patients, dobutamine stress echocardiography is of limited value, since it systematically induces a significant reduction in the degree of MR.[24]

Barreiro et al. studied 408 elderly patients undergoing isolated AVR.[7] Using multivariate analysis, preoperative MR was independently predictive of a higher mortality; survival was $40 \%$ in 338 patients without or with mild preoperative MR, and $15 \%$ in the 70 patients with moderate MR ( $\mathrm{p}=0.04)$. Patients with persistent or worsening MR after AVR tended to have a lower 5-year survival (58\% versus $72 \%$ ). Similar data were observed by Vanden Eynden et al., who found a trend towards better 10-year survival in patients with improved postoperative MR ( $\mathrm{p}=0.072)$.[25] There is thus some evidence linking perioperative MR and long-term prognosis. A causal relationship is, however, debatable. Moreover, the beneficial effects of correcting moderate MR during aortic surgery have not yet been demonstrated. 


\section{Does isolated AVR affect the severity of MR?}

When MR is less-than severe, decision making regarding any intervention can be difficult, and will be influenced by the expectation that MR may spontaneously improve, by the increased risk of double-valve surgery, and by the increased risk of future reoperation if postoperative MR remains or becomes clinically significant. Indeed, as LV cavity pressure drops early after surgery, the transmitral pressure gradient will decrease, resulting in an improvement in the MR.[26] Of note, this observation differs from the changes reported after acute afterload reduction induced by vasodilator therapy in heart failure patients with dynamic $\mathrm{MR}$, in which the systolic blood pressure to left atrial pressure gradient remains unaltered.[27] Early improvement in MR after AVR might also be determined by an acute reverse LV remodelling effect, including a reduction in LV end-diastolic volume. Changes in LV shape and geometry may also contribute to improved MR through a decrease in mitral tethering forces.[28,29] Whether this mechanism occurs in the early postoperative period has been debated,[26] but it may become more significant in the long-term follow-up.[19] These data suggest that in patients with an enlarged LV, postoperative improvement in MR is related to both LV reverse remodelling and reduction in transmitral pressure gradient, whereas in patients with a small LV cavity, the decrease in pressure gradient after surgery represents the predominant mechanism.

In the early postoperative period, the reduction in MR severity, as assessed by the ratio of the regurgitant jet to left atrial area (colour flow jet mapping), and by the regurgitant volume (37\% and $40 \%$, respectively) was significantly larger than the decrease in the effective regurgitant orifice ( $25 \%$ ), emphasizing the determinant role of the decrease in LV to left atrial systolic pressure gradient.[26] The preoperative effective regurgitant orifice was affected to a much lesser extent than more load-dependent variables, such as colour flow mapping and regurgitant volume (a typical example is shown in Figure 2). This highlights the importance of preoperative quantification of MR with the effective regurgitant orifice, even though the latter parameter is not completely load independent.[30,31] Vena contracta width, which has been shown to be less dependent on hemodynamic variations and correlates reasonably well with quantitative Doppler estimates of regurgitant orifices, might be used to corroborate the quantitative results.[10,32]

When preoperative MR is less-than severe and not being considered for repair or replacement at the time of AVR for AS (Table 2), most studies have described improved MR after surgery in most patients. However, conflicting reports exist regarding the exact number of patients with improved MR after surgery, and the magnitude of the improvement. Only $40 \%$ of patients had reduced MR severity in a study by Adams and Otto.[4] Brasch et al. reported that in a sub-group of patients with moderate-to-severe MR, 56\% (9 patients) had no change in MR after AVR.[17] By contrast, MR improved in more than $80 \%$ of the patients in a study by Harris et al.[18] These discrepancies may be related to the different inclusion criteria in terms of MR aetiology (functional or organic) and severity, and to the timing of the postoperative ultrasound examination (Table 2). Importantly, only qualitative or semi-quantitative methods of MR evaluation have been used in most studies.[3-10,17-19,25] In addition, the majority of these studies were retrospective in nature. The frequent occurrence of improvement in MR has, however, been confirmed by more recent prospective data.[5,26] An improvement in MR was also reported after percutaneous transarterial AVR using the Cribier Edwards balloonexpandable stent valve, with an MR grade decreasing from a median of 2 (moderate) to 1 (mild) at discharge $(\mathrm{p}=0.01)$. In this series of high risk patients with AS, 53\% of successfully implanted patients had moderate to severe MR at baseline, decreasing to $33 \%$ at discharge, and to $24 \%$ at 12 months.[33] The presence of grade 2 MR might however, be a contraindication to the CoreValve ReValving System. Indeed, its LV component may 
interfere with the mitral valve function by restricting anterior leaflet mobility or disrupting secondary chordae.[34]

\section{Predictive factors of postoperative MR improvement}

Several factors predictive of improvement in MR have been described (Table 2). The magnitude of preoperative MR itself was shown to correlate with the postoperative improvement in MR; $[3,10,26]$ namely, the more severe the MR, the greater the potential for improvement, which is not an unexpected finding. The functional nature of MR was also found to be predictive of improvement. In their retrospective review, Barreiro et al. observed that $82 \%$ of patients with functional MR improved postoperatively, whereas in $50 \%$ with myxomatous MR and in $80 \%$ with calcified disease, the MR remained unchanged or worsened.[7] Similarly, Vanden Eynden et al. found that isolated ischaemic and functional MR were the only preoperative factors predictive of MR improvement after AVR.[25] In contrast, we did not observe greater MR improvement in the early postoperative period in patients with functional compared to patients with organic MR.[26] This discrepancy may be related to the relatively small number of patients with purely functional MR in the study by Barreiro,[7] and to the different time-delay for the postoperative echocardiography, reaching up to one year in the study by Vanden Eynden et al.[25] In addition, in line with our observation is a report by Kizilbach et al., which noted that aetiologic determination of MR did not always predict whether the regurgitant orifice is dynamic or fixed in individual patients.[30] The fact that reduced LV function, increase in LV size, and larger preoperative LV mass have also been associated with a decrease in MR $[5,17,18]$ also supports the importance of the functional nature of MR in predicting post-operative improvement.

A role of revascularization in the post-operative improvement in MR is advocated by a greater improvement in MR in the presence of coronary lesions compared to patients with functional MR but no coronary artery disease, suggesting a beneficial effect of coronary revascularization, $[9,19]$ as may also be the case after coronary artery bypass grafting in patients with ischaemic MR without AS.[35]

A small left atrial size predicted a lower postoperative MR in studies by Ruel et al. and Waisbren et al.,[8,10] but the opposite was found by Harris et al.[18] The impact of aortic prosthesis size, and thus of patient/prosthesis mismatch, was addressed in a study by Waisbren et al., who reported that there was no independent relationship of aortic prosthesis size with the change in MR nor with postoperative morbidity and mortality.[10] However, very few patients had patient/prosthesis mismatch in this series. In addition, the effective orifice area was derived from the manufacturer's published values of projected in vivo effective orifice area, and not from the continuity equation. This issue, therefore, deserves further study.

\section{Postoperative increase in MR severity}

While some studies reported no increase in MR grade after surgery,[3,19] other authors have noted some increases in MR severity. The incidence of increasing severity of MR was, however, limited, occurring in 4 to $14 \%$ of patients in most studies, $[4,5,7,9,17,25]$ and affecting $30 \%$ of patients in just one study.[6] Although the predictors of such an increase are poorly understood, the increase was generally very limited. This was confirmed by a quantitative approach, with the increase in effective regurgitant orifice ranging from 0.1 to 4.8 $\mathrm{cm}^{2}$ (mean $2.1 \mathrm{~cm}^{2}$ ) and in regurgitant volume from 1.1 to $8.1 \mathrm{ml}$ (mean $3.4 \mathrm{ml}$ ).[26]

\section{Management of severe preoperative MR}

When MR is severe, double-valve surgery is generally considered. However, even in this situation, some regression may occur even if the mitral valve is not operated on. Although 
many studies did not include any patients with severe MR, $[4,7,9,10,20,25,26]$ there are data on 40 patients with severe MR who did not undergo surgical mitral valve intervention.[3,5,6,17-19] Interestingly, 90\% of these patients had an improvement of at least one grade, and for the majority of them, of at least two grades. Therefore, selected patients with severe AS and severe MR may be considered for isolated AVR (or transcatheter aortic valve implantation) if the operative risk of double-valve surgery is deemed unacceptable. Thus, the decision to operate on both valves requires assessment of MR severity, preferably by the calculation of the effective regurgitant orifice, knowledge of the functional or organic aetiology of MR and determination of the suitability for mitral valve repair. Finally, the decision-making process will be influenced by the age, the presence of co-morbidities, and the assessment of operative risk (Figure 3). This will allow a tailored approach: Double-valve replacement, AVR plus mitral valve repair, isolated AVR, or transcatheter aortic valve implantation for patients deemed at the highest surgical risk. It is recommended that chronic functional ischaemic MR, when severe (that is, when the ERO is $\geq 20 \mathrm{~mm}^{2}$ ) should be corrected at the time of bypass surgery (European Society of Cardiology guidelines, level IC).[36] Because of the frequent spontaneous downgrading of MR after isolated AVR, we speculate that the threshold for an associated mitral procedure should be increased up to 30 $\mathrm{mm}^{2}$ when correction of severe ischaemic/functional MR is being contemplated during AVR. By contrast, because MR of organic origin does not improve in a substantial proportion of patients after isolated AVR, the conventional ERO threshold of $40 \mathrm{~mm}^{2}$ [36] may be decreased to $30 \mathrm{~mm}^{2}$, to avoid the increased risk of future reoperation on the mitral valve. If, after careful clinical and echocardiographic assessment, it is still unclear whether to operate on the mitral valve, one option may be to perform balloon dilatation of the aortic valve and to assess the effects of this intervention on MR; persistence of severe MR in this situation may offer support for double-valve surgery, although this approach has not been validated.

\section{Conclusions}

Despite an increase in peri-operative and postoperative risk after a combined procedure, detection of severe MR in a patient with AS requiring AVR suggests the need for a double valve procedure. If the operative risk of double valve surgery is deemed unacceptable, selected patients with associated severe MR may be considered for isolated AVR (or transcatheter aortic valve implantation). When feasible, mitral valve repair will be the preferred approach. If MR is less-than severe, spontaneous down-grading is likely to occur after isolated AVR, but this down-grading effect will be more pronounced for regurgitant volume than for the effective regurgitant orifice. A functional aetiology of MR is likely to predict improvement on the long-term. Because the reduction in left ventricular systolic pressure contributes to the decrease in regurgitant volume and to colour flow area, preoperative quantitative assessment of MR should be performed by measurement of the effective regurgitant orifice to predict postoperative MR severity.

Acknowledgements: Philippe Unger has received a grant from the Fonds pour la Chirurgie Cardiaque Competing interests: none

The Corresponding Author has the right to grant on behalf of all authors and does grant on behalf of all authors, an exclusive licence (or non exclusive for government employees) on a worldwide basis to the BMJ Publishing Group Ltd and its Licensees to permit this article (if accepted) to be published in HEART and any other BMJPGL products to exploit all subsidiary rights, as set out in our licence. 


\section{References:}

1. Brener SJ, Duffy CI, Thomas JD, et al.. Progression of aortic stenosis in 394 patients: relation to changes in myocardial and mitral valve dysfunction. J Am Coll Cardiol 1995;25:305-10.

2. Timmis SB, Kirsh MM, Montgomery DG, et al. Evaluation of left ventricular ejection fraction as a measure of pump performance in patients with chronic mitral regurgitation. Catheter Cardiovasc Interv. 2000;49:290-6.

3. Tunick PA, Gindea A, Kronzon I. Effect of aortic valve replacement for aortic stenosis on severity of mitral regurgitation. Am J Cardiol 1990;65;1219-1221.

4. Adams PB, Otto CM. Lack of improvement in coexisting mitral regurgitation after relief of valvular aortic stenosis. Am J Cardiol 1990;66:105-107.

5. Tassan-Mangina S, Metz D, Nazeyllas P, et al. Factors determining early improvement in mitral regurgitation after aortic valve replacement for aortic valve stenosis: a transthoracic and transesophageal prospective study. Clin Cardiol 2003;26:127-31.

6. Moazami N, Diodato MD, Moon MR, et al. Does functional mitral regurgitation improve with isolated valve replacement? J Card Surg 2004;19:444-8.

7. Barreiro CJ, Patel ND, Fitton TP, et al. Aortic valve replacement and concomitant mitral valve regurgitation in the elderly. Impact on survival and functional outcome. Circulation 2005; 112[suppl I]:I-443-7.

8. Ruel M, Kapila V, Price J, et al. Natural history and predictors of outcome in patients with concomitant functional mitral regurgitation at the time of aortic valve replacement. Circulation 2006;114[suppl I]:I-541-6.

9. Caballero-Borrego J, Gómez-Doblas JJ, Cabrera-Bueno F, et al. Incidence, associated factors and evolution of non-severe functional mitral regurgitation in patients with severe aortic stenosis undergoing aortic valve replacement. Eur J Cardiothorac Surg 2008;34:62-6.

10. Waisbren EC, Stevens LM, Avery EG, et al. Changes in mitral regurgitation after replacement of the stenotic aortic valve. Ann Thorac Surg 2008;86:56-62.

11. Cartwright RS, Giacobine JW, Ratan RS, et al. Combined aortic and mitral valve replacement. J Thorac Cardiovasc Surg 1963;45:35-42.

12. Society of Thoracic Surgeon Adult Cardiovascular Surgery Database 2005 http://sts.org/documents/pdf/Spring2005STS-ExecutiveSummary.pdf

13. Arom KV, Nicoloff DM, Kersten TE, et al. Ten-year follow-up study of patients who had double valve replacement with the St. Jude Medical prosthesis, J Thorac Cardiovasc Surg 1989;98:1008-15.

14. Mueller XM, Tevaearai HT, Stumpe F, et al. Long-term results of mitral-aortic valve operations. J Thorac Cardiovasc Surg 1998;115:1298-309.

15. Gillinov AM, Blackstone EH, Cosgrove DM 3rd, et al. Mitral valve repair with aortic valve replacement is superior to double valve replacement. J Thorac Cardiovasc Surg 2003;125:1372-87.

16. Talwar S, Mathur A, Choudhary SK, et al. Aortic Valve Replacement With Mitral Valve Repair Compared With Combined Aortic and Mitral Valve. Ann Thorac Surg 2007;84:1219-25.

17. Brasch AV, Khan SS, DeRobertis MA, et al. Change in mitral regurgitation severity after aortic valve replacement for aortic stenosis. Am J Cardiol 2000;85:1271-4.

18. Harris KM, Malenka DJ, Haney MF, et al. Improvement in mitral regurgitation after aortic valve replacement. Am J Cardiol 1997;80:741-5.

19. Christenson JT, Jordan B, Bloch A, et al. Should a regurgitant mitral valve be replaced with a stenotic aortic valve? Tex Heart Inst J 2000;27:350-5. 
20. Absil B, Dagenais F, Mathieu P, et al. Does moderate mitral regurgitation impact early mid-term clinical outcome in patients undergoing isolated aortic valve replacement for aortic stenosis? Eur J Cardiothorac Surg 2003;24:217-22.

21. Lancellotti P, Karsera D, Tumminello G, et al .Determinants of an abnormal response to exercise in patients with asymptomatic valvular aortic stenosis. Eur J Echocardiogr. 2008;9:338-43.

22. Lancellotti P, Marwick T, Pierard LA. How to manage ischaemic mitral regurgitation. Heart 2008;94:1497-502.

23. Van Pelt NC, Stewart RAH, Legget ME, et al. Longitudinal left ventricular contractile dysfunction after exercise in aortic stenosis. Heart 2007;93:732-8.

24. Vanden Eynden F, Bouchard D, El-Hamamsy I, et al. Effect of aortic valve replacement for aortic stenosis on severity of mitral regurgitation. Ann Thorac Surg 2007;83:1279-84.

25. Ennezat PV, Marechaux S, Iung B, et al. Exercise testing and exercise stress echocardiography in asymptomatic aortic valve stenosis. Heart 2008;doi:10.1136/hrt.2008.150011

26. Unger P, Plein,D, Van Camp,G, et al. Effects of valve replacement for aortic stenosis on mitral regurgitation. Am J Cardiol 2008;102:1378-82

27. Rosario LB, Stevenson LW, Solomon SD, et al. The mechanism of decrease in dynamic mitral regurgitation during heart failure treatment: importance of reduction in the regurgitant orifice size. J Am Coll Cardiol 1998;32:1819-24.

28. Yiu SF, Enriquez-Sarano M, Tribouilloy C, et al. Determinants of the degree of functional mitral regurgitation in patients with systolic left ventricular dysfunction: A quantitative clinical study. Circulation 2000;102:1400-6.

29. Kono T, Sabbah HN, Rosman H, et al. Left ventricular shape is the primary determinant of functional mitral regurgitation in heart failure. J Am Coll Cardiol 1992;20:1594-8.

30. Kizilbash AM, Willett DL, Brickner ME, et al. Effects of afterload reduction on vena contracta width in mitral regurgitation. J Am Coll Cardiol 1998;32:427-31.

31. Calabrò R, Pisacane C, Pacileo G, et al. Hemodynamic effects of a single oral dose of enalapril among children with asymptomatic chronic mitral regurgitation. Am Heart J. 1999;138:955-61.

32. Heinle SK, Hall SA, Brickner ME, et al. Comparison of vena contracta width by multiplane transesophageal echocardiography with quantitative Doppler assessment of mitral regurgitation. Am J Cardiol 1998;81:175-9.

33. Webb JG, Pasupati S, Humphries K, et al. Percutaneous transarterial aortic valve replacement in selected high-risk patients with aortic stenosis. Circulation 2007;116:755-63.

34. Chin D. Echocardiography for transcatheter aortic valve implantation. Eur J Echocardiogr 2009;10:i21-9.

35. Wong DR, Agnihotri AK, Hung JW, et al. Long-term survival after surgical revascularization for moderate ischemic mitral regurgitation. Ann Thorac Surg 2005;80:570-7.

36. Vahanian A, Baumgartner H, Bax J, et al. Task Force on the Management of Valvular Heart Disease of the European Society of Cardiology; ESC Committee for Practice Guidelines. Guidelines on the management of valvular heart disease: The Task Force on the Management of Valvular Heart Disease of the European Society of Cardiology. Eur Heart J 2007;28:230-68. 
Figure 1: Pathophysiology of interactions between aortic stenosis and mitral regurgitation (see text for details). LV, left ventricle; LA, left atrium; EF, ejection fraction

Figure 2: Example of changes in mitral regurgitation induced by aortic valve replacement. The proximal flow-convergence region is seen preoperatively and after aortic valve replacement. A $32 \%$ reduction of regurgitant volume (Rvol) reduction is seen, with a lesser change $(11 \%)$ in calculated effective regurgitant orifice (ERO). R, proximal isovelocity surface area radius; Alias, aliasing velocity; Max V, maximal regurgitant flow velocity; TVI, time velocity integral of the regurgitant jet

Figure 3: Proposed decisional algorithm for management of mitral regurgitation (MR) in patients with aortic stenosis requiring surgery; ERO, effective regurgitant orifice; PASP, pulmonary artery systolic pressure; LAD, left atrial diameter; AVR, aortic valve replacement 
Table 1: Prevalence of mitral regurgitation in patients undergoing isolated aortic valve replacement

\begin{tabular}{|c|c|c|c|c|}
\hline Authors, Year & Exclusion criteria & $\begin{array}{c}\text { Number of } \\
\text { patients }\end{array}$ & $\begin{array}{l}\text { Percentage of patients } \\
\text { with preoperative MR }\end{array}$ & $\begin{array}{l}\text { Method of MR } \\
\text { assessment }\end{array}$ \\
\hline $\begin{array}{l}\text { Tunick } \\
1990[3]\end{array}$ & None & 44 & $61 \%$ with $\geq$ mild MR & Colour flow mapping \\
\hline $\begin{array}{l}\text { Adams } \\
1990[4]\end{array}$ & None & $56^{*}$ & $82 \%$ with $\geq 1+M R$ & $\begin{array}{l}\text { Pulsed wave Doppler } \\
\text { mapping }\end{array}$ \\
\hline $\begin{array}{l}\text { Tassan-Mangina } \\
2003[5]\end{array}$ & $\begin{array}{l}\text { Severe AR } \\
\text { Unstable haemodynamic state } \\
\text { Arrhythmia }\end{array}$ & 30 & $90 \%$ with $\geq$ mild $\mathrm{MR}$ & Colour flow mapping \\
\hline $\begin{array}{l}\text { Moazami } \\
2004[6]\end{array}$ & $\begin{array}{l}\text { Organic mitral valve disease } \\
\text { Previous sternotomy or mitral } \\
\text { valve surgery }\end{array}$ & 250 & $78 \%$ with $\geq$ mild $\mathrm{MR}$ & Colour flow mapping \\
\hline $\begin{array}{l}\text { Barreiro } \\
2005 \text { [7] }\end{array}$ & $\begin{array}{l}\text { Need for concomitant bypass } \\
\text { surgery }\end{array}$ & 408 & $\begin{array}{c}17.2 \% \text { with } \geq \text { moderate } \\
\text { MR }\end{array}$ & Colour flow mapping \\
\hline $\begin{array}{l}\text { Ruel } \\
2006[8]\end{array}$ & $\begin{array}{l}\text { Organic mitral valve disease } \\
\text { Patients who did not survive the } \\
\text { operation }\end{array}$ & 848 & $12.6 \%$ with $\geq 2+\mathrm{MR}$ & $\begin{array}{c}2003 \text { American Society of } \\
\text { Echocardiography } \\
\text { recommendations }\end{array}$ \\
\hline $\begin{array}{l}\text { Caballero- } \\
\text { Borrego } \\
2008[9]\end{array}$ & $\begin{array}{l}\text { Predominant AR } \\
\text { Predominant coronary artery } \\
\text { disease } \\
\text { Type A aortic dissection } \\
\text { Organic mitral valve disease } \\
\text { MR secondary to SAM }\end{array}$ & 577 & $\begin{array}{c}26.5 \% \text { with non-severe } \\
\text { MR }\end{array}$ & $\begin{array}{l}\text { Colour flow and pulsed } \\
\text { wave Doppler mapping, } \\
\text { pulmonary vein flow }\end{array}$ \\
\hline $\begin{array}{l}\text { Waisbren } \\
2008[10]\end{array}$ & $\begin{array}{l}\text { Structural mitral valve disease } \\
\text { Combined procedure (CABG) } \\
\text { Endocarditis } \\
\text { Right heart valve procedure } \\
\text { Moderate or severe AR }\end{array}$ & 227 & $74 \%$ with moderate MR & Vena contracta width \\
\hline
\end{tabular}

*Among these patients, 32 had aortic balloon valvuloplasty $\mathrm{MR}$, mitral regurgitation; $\mathrm{AR}$, aortic regurgitation; $\mathrm{CABG}$, coronary artery bypass grafting; SAM, systolic anterior motion of the mitral valve 
Table 2: Impact of isolated aortic valve replacement on mitral regurgitation

\begin{tabular}{|c|c|c|c|c|c|c|}
\hline $\begin{array}{l}\text { First author, } \\
\text { Year }\end{array}$ & $\begin{array}{c}\text { Aetiology of } \\
\text { MR }\end{array}$ & \begin{tabular}{|c|} 
Number of \\
patients with \\
preoperative MR \\
who had a \\
postoperative \\
echo study \\
\end{tabular} & $\begin{array}{l}\text { Timing of the } \\
\text { postoperative } \\
\text { echo } \\
\text { examination }\end{array}$ & $\begin{array}{c}\text { \% of patients } \\
\text { with } \\
\text { improvement in } \\
\text { MR }\end{array}$ & $\begin{array}{l}\text { Preoperative predictive } \\
\text { factors of MR } \\
\text { improvement }\end{array}$ & $\begin{array}{l}\text { Method of MR } \\
\text { assessment }\end{array}$ \\
\hline $\begin{array}{l}\text { Tunick } \\
1990[3]\end{array}$ & $\begin{array}{c}\text { Functional } \\
\text { Organic }\end{array}$ & $\begin{array}{c}\mathrm{N}=27 \text { with } \geq \text { mild } \\
\mathrm{MR}\end{array}$ & $\begin{array}{l}\text { 3-388 days, } \\
\text { mean } 58 \text { days }\end{array}$ & $67 \%$ & MR severity & $\begin{array}{l}\text { Colour flow } \\
\text { mapping }\end{array}$ \\
\hline $\begin{array}{l}\text { Adams } \\
1990[4]\end{array}$ & $\begin{array}{c}\text { Organic } \\
\text { Functional }\end{array}$ & $\begin{array}{c}\mathrm{N}=46 \text { with } \geq \text { mild } \\
\mathrm{MR}\end{array}$ & $\begin{array}{c}\text { 1-750 days } \\
\text { Mean } 176 \text { days }\end{array}$ & 27 & $\begin{array}{l}\text { No predictive factor } \\
\text { found }\end{array}$ & $\begin{array}{c}\text { Pulsed wave } \\
\text { Doppler mapping }\end{array}$ \\
\hline $\begin{array}{l}\text { Harris } \\
1997[18]\end{array}$ & Functional & $\begin{array}{c}\mathrm{N}=28 \text { with } \geq \text { mild } \\
\mathrm{MR}\end{array}$ & $2.5 \pm 4.2$ months & $82 \%$ & $\begin{array}{l}\text { Low LV fractional area } \\
\text { Large left atrial size }\end{array}$ & $\begin{array}{l}\text { Colour flow } \\
\text { mapping }\end{array}$ \\
\hline $\begin{array}{l}\text { Brasch } \\
2000[17]\end{array}$ & $\begin{array}{c}\text { Organic } \\
\text { Functional }\end{array}$ & $\begin{array}{l}\mathrm{N}=16 \text { with } \geq \\
\text { moderate } \mathrm{MR}\end{array}$ & $2.2 \pm 5.1$ months & $44 \%$ & LV mass & $\begin{array}{l}\text { Colour flow } \\
\text { mapping }\end{array}$ \\
\hline $\begin{array}{l}\text { Christenson, } \\
2000 \text { [19] }\end{array}$ & Functional & $\begin{array}{c}\mathrm{N}=58 \text { with } \geq \text { mild } \\
\mathrm{MR}\end{array}$ & \begin{tabular}{|c|}
$\begin{array}{c}1 \text { week } \\
\text { and }\end{array}$ \\
2.7 to 7.2 months
\end{tabular} & $\begin{array}{l}46 \% \text { at one week } \\
60 \% \text { at late } \\
\text { follow-up if } \geq \\
\text { grade II preop }\end{array}$ & $\begin{array}{l}\text { Presence of coronary } \\
\text { artery disease }\end{array}$ & $\begin{array}{l}\text { Colour flow } \\
\text { mapping }\end{array}$ \\
\hline $\begin{array}{l}\text { Tassan- } \\
\text { Mangina } \\
2003[5]\end{array}$ & $\begin{array}{c}\text { Functional } \\
\text { in all except } \\
2 \text { patients }\end{array}$ & $\begin{array}{c}\mathrm{N}=23 \text { with } \geq \text { mild } \\
\text { MR on TTE }\end{array}$ & $19 \pm 10$ days & $61 \%$ & $\begin{array}{l}\text { Peak velocity of tricuspid } \\
\text { regurgitant jet } \\
\text { Indexed LV mass }\end{array}$ & $\begin{array}{l}\text { Colour flow } \\
\text { mapping }\end{array}$ \\
\hline $\begin{array}{l}\text { Moazami } \\
2004[6]\end{array}$ & Functional & $\begin{array}{c}\mathrm{N}=80 \text { with } \geq \text { mild } \\
\mathrm{MR}\end{array}$ & $>60$ days & $45 \%$ & $\begin{array}{l}\text { History of previous } \\
\text { myocardial infarction }\end{array}$ & $\begin{array}{l}\text { Colour flow } \\
\text { mapping }\end{array}$ \\
\hline $\begin{array}{l}\text { Barreiro } \\
2005 \text { [7] }\end{array}$ & $\begin{array}{c}\text { Organic } \\
\text { Functional }\end{array}$ & $\begin{array}{l}\mathrm{N}=70 \text { with } \geq \\
\text { moderate } \mathrm{MR}\end{array}$ & $\begin{array}{c}\text { Early } \\
\text { postoperative }\end{array}$ & $\begin{array}{c}82 \% \text { if functional } \\
35 \% \text { if organic }\end{array}$ & Functional MR & $\begin{array}{l}\text { Colour flow } \\
\text { mapping }\end{array}$ \\
\hline $\begin{array}{l}\text { Ruel } \\
2006[8]\end{array}$ & Functional & $\begin{array}{c}\mathrm{N}=107 \text { with } \geq 2+ \\
\mathrm{MR}\end{array}$ & 18 months & $\begin{array}{c}44 \% \text { if } 2 \\
\text { preoperative risk } \\
\text { factor } \\
74 \% \text { if } 1 \\
\text { preoperative risk } \\
\text { factor } \\
78 \% \text { if no } \\
\text { preoperative risk } \\
\text { factor }\end{array}$ & $\begin{array}{l}\text { No enlarged left atrium } \\
(>5 \mathrm{~cm}) \\
\text { No low preoperative peak } \\
\text { aortic pressure gradient }(< \\
60 \mathrm{~mm} \mathrm{Hg}) \\
\text { No chronic atrial } \\
\text { fibrillation }\end{array}$ & $\begin{array}{c}2003 \text { American } \\
\text { Society of } \\
\text { Echocardiography } \\
\text { recommendations }\end{array}$ \\
\hline $\begin{array}{l}\text { Vanden Eynden } \\
2007[24]\end{array}$ & $\begin{array}{c}\text { Organic } \\
\text { Functional }\end{array}$ & $\begin{array}{l}\mathrm{N}=80 \text { with } \geq \\
\text { moderate } \mathrm{MR}\end{array}$ & 1 year & $35 \%$ & $\begin{array}{l}\text { Functional (including } \\
\text { ischaemic) MR }\end{array}$ & $\begin{array}{c}\text { Colour flow and } \\
\text { pulsed wave } \\
\text { Doppler mapping, } \\
\text { pulmonary vein } \\
\text { flow }\end{array}$ \\
\hline $\begin{array}{l}\text { Caballero- } \\
\text { Borrego } \\
2008[9]\end{array}$ & Functional & $\begin{array}{c}\mathrm{N}=153 \text { with non- } \\
\text { severe MR }\end{array}$ & $\begin{array}{l}\text { Before hospital } \\
\text { discharge }\end{array}$ & $72 \%$ & $\begin{array}{l}\text { Presence of coronary } \\
\text { artery disease, absence of } \\
\text { diabetes and of } \\
\text { pulmonary hypertension }\end{array}$ & $\begin{array}{c}\text { Colour flow and } \\
\text { pulsed wave } \\
\text { Doppler mapping, } \\
\text { pulmonary vein } \\
\text { flow } \\
\end{array}$ \\
\hline $\begin{array}{l}\text { Waisbren } \\
2008[10]\end{array}$ & $\begin{array}{l}\text { Functional } \\
\text { No CABG }\end{array}$ & $\begin{array}{c}\mathrm{N}=60 \text { with } \\
\text { no/mild } \mathrm{MR} \\
\mathrm{N}=167 \text { with } \geq \\
\text { moderate } \mathrm{MR}\end{array}$ & Intraoperative & $\begin{array}{c}66 \% \text { of } \\
\text { preoperative } \\
\text { moderate MR }\end{array}$ & $\begin{array}{l}\text { MR severity } \\
\text { Trace or mild aortic } \\
\text { insufficiency } \\
\text { Left atrial size }<4.5 \mathrm{~cm} \\
\text { Congestive heart failure }\end{array}$ & $\begin{array}{l}\text { Vena contracta } \\
\text { width }\end{array}$ \\
\hline
\end{tabular}




\begin{tabular}{|c|c|c|c|c|c|c|}
\hline $\begin{array}{l}\text { Unger } \\
2008[26]\end{array}$ & $\begin{array}{c}\text { Functional } \\
\text { Organic }\end{array}$ & $\begin{array}{c}\mathrm{N}=52 \text { with } \geq \text { mild } \\
\mathrm{MR}\end{array}$ & $\begin{array}{l}\text { Before hospital } \\
\text { discharge }\end{array}$ & $\begin{array}{l}69 \% \text { decrease in } \\
\text { effective } \\
\text { regurgitant } \\
\text { orifice } \\
87 \% \text { decrease in } \\
\text { regurgitant } \\
\text { volume }\end{array}$ & $\begin{array}{l}\text { MR severity } \\
\text { Mitral coaptation height }\end{array}$ & PISA \\
\hline
\end{tabular}

MR, mitral regurgitation; LV, left ventricle; TTE: transthoracic echocardiography; PISA, proximal isovelocity surface area method; $\mathrm{CABG}$, coronary artery bypass grafting 


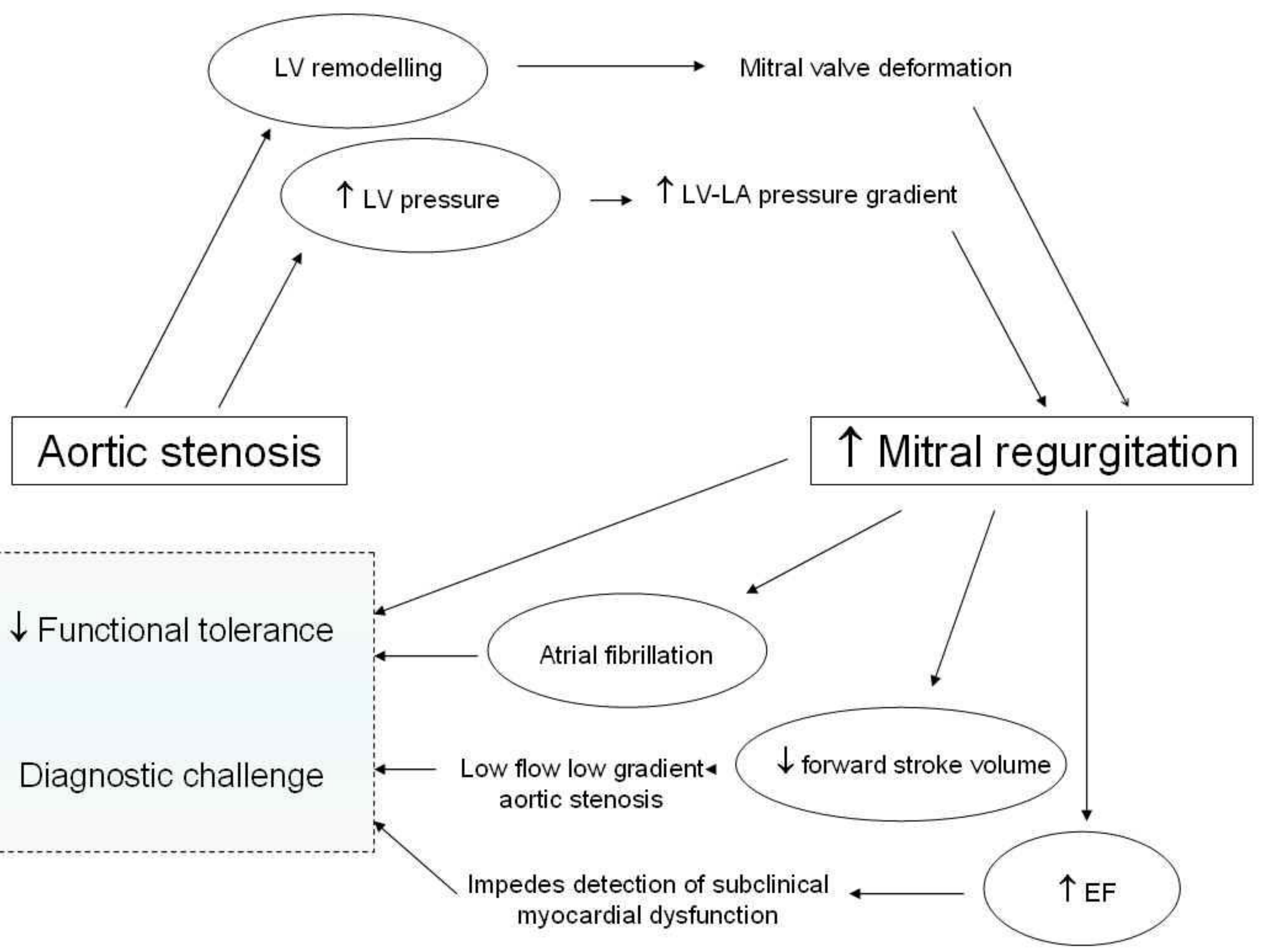


Preoperative

\section{Postoperative}

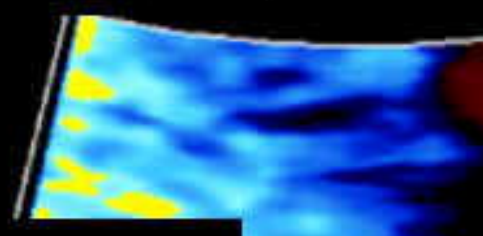

$\mathrm{R} 0.90 \mathrm{~cm}$

Alias $31 \mathrm{~cm} / \mathrm{s}$

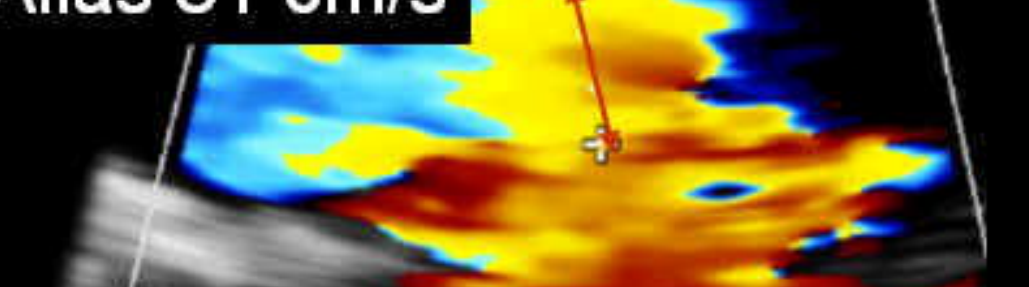

Max V $580 \mathrm{~cm} / \mathrm{s}$ VTI $150 \mathrm{~cm}$

ERO $0.27 \mathrm{~cm}^{2}$ RVol $41 \mathrm{ml}$
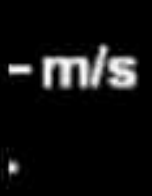

$-2.0$

$--4.0$

$--6.0$
ERO $0.24 \mathrm{~cm}^{2}$

$\mathrm{RVol} 28 \mathrm{ml}$
$\mathrm{R} 0.77 \mathrm{~cm}$

Alias $31 \mathrm{~cm} / \mathrm{s}$

$\operatorname{Max} V 490 \mathrm{~cm} / \mathrm{s}$ VTI $120 \mathrm{~cm}$ 


\section{Symptomatic Aortic Stenosis}

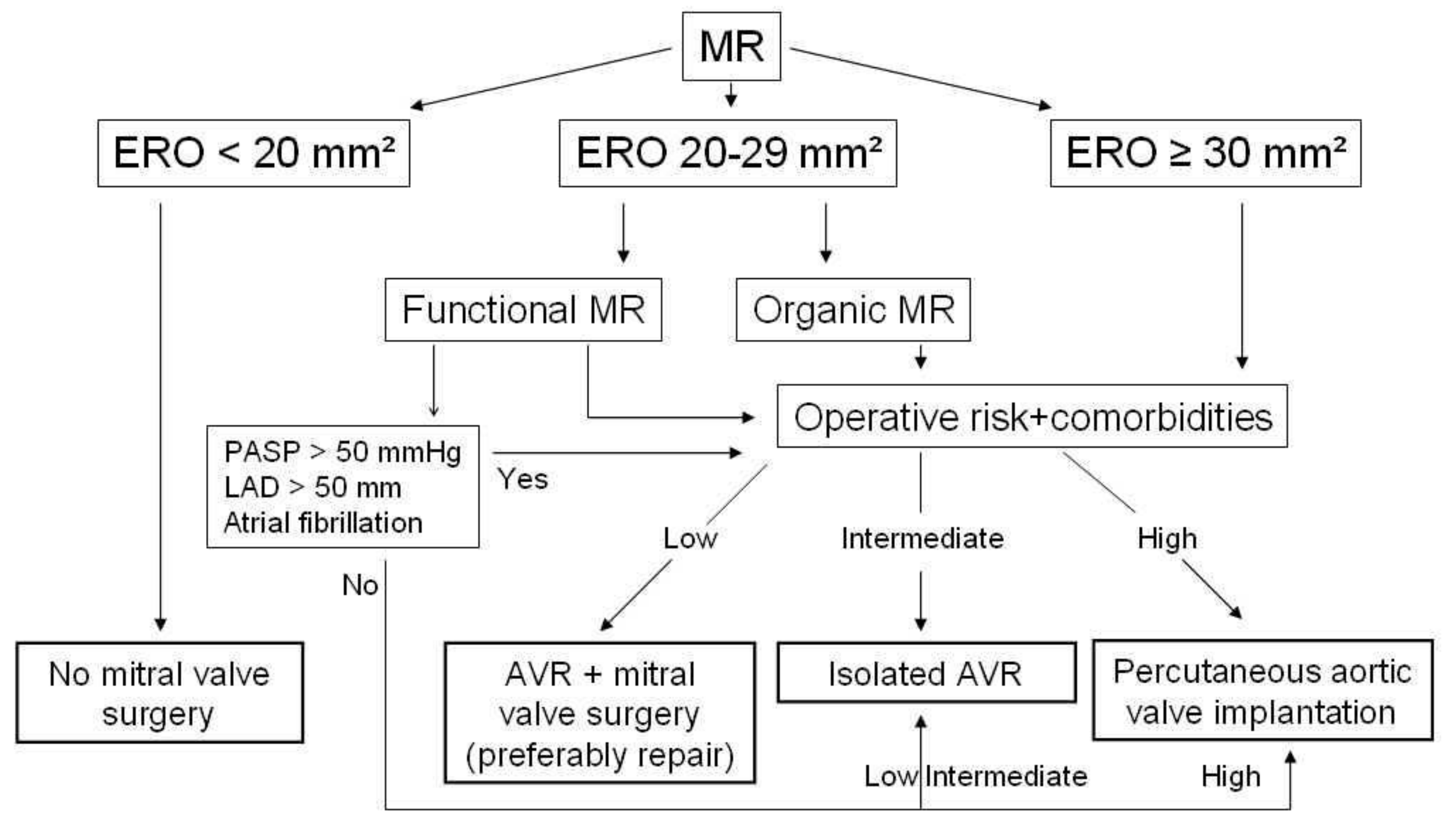

Surgical Risk 